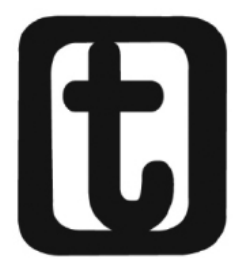

\title{
APROPRIAÇÃO CAPITALISTA DA CIÊNCIA E TECNOLOGIA NA AGRICULTURA: APONTAMENTOS PARA UM DEBATE SOBRE TRANSGÊNICOS E NANOTECNOLOGIAS
}

Capitalist appropriation of science and technology in agriculture: notes for a debate about transgenics and nanotechnology

\section{Pedro Ivan Christoffoli'}

\section{INTRODUÇÃO}

O advento dos transgênicos e da biotecnologia e seu uso cada vez mais amplo na agricultura e em outros segmentos da atividade humana nos colocam uma série de preocupações em relação aos impactos econômicos, ambientais e para a saúde humana. Também nos leva a reflexão acerca do papel da ciência e tecnologia em sua relação com a exploração dos trabalhadores sob o sistema capitalista. Este texto procura discutir esse último aspecto, a partir principalmente das teses de Marx e de outros autores.

\section{SUJEIÇÃO FORMAL E SUJEIÇÃO REAL DO TRABALHO AO CAPI- TAL NA AGRICULTURA E OS TRANSGÊNICOS}

Ao discutir o movimento de reorganização do trabalho na agricultura pelo capital, como forma de alcançar a maximização das taxas de lucro, o processo de subsunção tende a acelerar-se

\footnotetext{
${ }_{1}$ Professor da Universidade Federal da Fronteira Sul (UFFS) Campus Laranjeiras do Sul (PR). Doutor em Desenvolvimento Sustentável pela Universidade de Brasília (UnB/CDS). Militante do setor de produção do Movimento dos Trabalhadores Rurais Sem Terra do Brasil (MST). E-mail: <pedroivanc@gmail.com>.
} 
com a introdução das tecnologias biológicas em geral e muito mais amplamente com os transgênicos.

O tempo de rotação do capital se constitui no tempo necessário para ocorrer um ciclo completo de reprodução ampliada do capital e é fundamental para a reprodução do sistema capitalista, tendo em vista que a redução do tempo em que se efetua o giro do capital em determinado setor permite elevar a taxa de lucro obtida. Em cada rotação completa do capital é que se realiza a apropriação da mais-valia gerada no processo de produção. Nesse sentido, para o capital, quanto mais rotações do ciclo de capital num dado tempo, maior será o volume acumulado (MARX, 1988). Por outro lado, quanto mais tempo demora esse ciclo, maior é o período em que um determinado quantum de capital fica imobilizado na forma de capital produtivo, e também, maior o risco de ocorrerem problemas para que se complete o ciclo ${ }^{2}$.

Para que esse ciclo de rotação do capital se acelere é necessário que a intensidade e o ritmo de trabalho sejam também acelerados e que a força produtiva do trabalho como um todo sofra contínua elevação. Nesse ponto do processo de reprodução do capital, ocorre a aparição do antagonismo entre o capital e o trabalho, um visando à aceleração máxima do processo, ao ponto de sua desumanização, outro buscando resistir a essa aceleração da exploração a que se sujeita involuntariamente.

Havendo resistências dos trabalhadores ao aceleramento do ritmo de trabalho, o capital procura desenvolver meios (despóticos ou não) para que esse processo se dê, resultando, no entanto, sempre na ótica do capital, na sujeição do trabalhador aos seus interesses. A esse processo de subordinação do trabalho ao capital Marx denominou de sujeição ou subsunção. E de forma geral o processo de subsunção aparece unido ao emprego da mecanização como forma externa ao trabalhador, de aceleração do processo de trabalho. Mas na agricultura há um emprego limitado da mecanização devido ao tempo de produção e às barreiras naturais (dificuldades no manejo dos solos, fenôme-

\footnotetext{
${ }^{2}$ Os problemas aqui referidos podem ser de ordem natural (no caso da agricultura fenômenos climáticos, p.ex.) ou econômicos (oscilações inesperadas de preços no mercado, obsolescência tecnológica, crises de superprodução, p. ex.).
} 
nos climáticos, etc.) que estabelecem limites para o tempo de rotação do capital.

O capital, no início de seu desenvolvimento, não tinha construído as ferramentas científicas e técnicas necessárias para a batalha de controle sobre as barreiras naturais representadas pela irreprodutibilidade da terra, pelas variações de tipos de solos e climas, pelos ciclos e ritmos da natureza, pela fisiologia de plantas e animais, etc. Não havia amadurecido as condições para impor sua dinâmica e sua visão de organização sobre o sistema produtivo empregado então na agricultura, arraigado ainda, em tradições seculares e disperso em milhões de unidades produtivas camponesas.

Na agricultura, a aplicação da mecanização ocorre em algumas aplicações restritas como o preparo da terra, o plantio e a colheita, o controle químico de pragas, doenças e plantas invasoras. Também a criação de aves e de gado leiteiro em sistemas confinados, onde se pode utilizar alto grau de mecanização e sistemas eletrônicos de controle de fornecimento de alimentos. Ainda, o emprego da cooperação direta no processo de trabalho na agricultura é mais restrito, pela tendência à redução absoluta no emprego da força de trabalho necessária, com o desenvolvimento das forças produtivas e o emprego de capital constante.

Há também os obstáculos econômicos, pois na agricultura a maioria dos equipamentos só é utilizada durante certos meses. Na indústria, eles funcionam durante todo o ano. $\mathrm{E}$ fatores como o relativo isolamento do meio rural, que torna mais difícil o reparo das máquinas. A introdução da divisão do trabalho encontra limitações naturais, objetivas, e limites trazidos pela existência do monopólio privado sobre a terra. Na agricultura, a redução da porosidade do trabalho necessariamente esbarra nos tempos da natureza. O fato de mecanizar a colheita pode reduzir o tempo de trabalho, mas não encurta o tempo de produção, senão marginalmente. Também o uso de herbicidas, que elimina as ervas espontâneas, reduzindo o tempo necessário a capina, não diminui o tempo de produção dos cultivos.

Desse modo, muitas vezes a busca de utilização do capital constante de forma mais racional se dá não pela redução direta do tempo de produção, mas pelo aumento do tempo de trabalho e de utilização do capital produtivo empregado. Isso se obtém pela intercalação de 
cultivos de uma mesma espécie, ou combinação de espécies diferentes, permitindo obter uma redução da porosidade do trabalho. Por exemplo, a extensão dos períodos de cultivo e o uso de variedades precoces e tardias possibilitam uma melhor utilização do capital pela ampliação do número de dias trabalhados durante o ano. Isto ocorreu na produção frutícola brasileira. A introdução de variedades precoces e tardias redistribuiu os períodos de safra ampliando-os, ainda que os limites naturais permaneçam presentes. Essa melhor utilização pode ocorrer pela redução no volume necessário de estruturas de armazenagem, pela utilização mais racional de tratores, colheitadeiras e caminhões, da força de trabalho, etc. Também é positivo para o capital o fato de que, com o escalonamento da produção, parte do capital reflua mais cedo viabilizando uma antecipação da realização da acumulação ampliada.

Os ganhos para o capital não passam necessariamente pelo encurtamento do ciclo produtivo, pois as barreiras naturais permanecem. O ideal para o capital seria uma autonomização em relação aos limites naturais, possibilitando o início da produção agrícola a qualquer momento, independente de solos e clima, realizada em etapas conexas, porém articuláveis de forma a permitir seu planejamento estrito, e que os volumes de produção se estabilizassem, assegurando para isso o controle sobre intempéries e variações climáticas extremas.

Marx (1968), nesse sentido, apontou para uma futura reunificação da agricultura à indústria em uma síntese superior, propiciada pelo desenvolvimento das forças produtivas na indústria (entendida aqui também a indústria de insumos e produtos para a agricultura, como também a indústria química, mecânica, genética, etc.). 0 modo de produção capitalista completa a ruptura dos laços primitivos que no começo uniam a agricultura e a manufatura. E cria as condições materiais para uma síntese nova, superior, para a união da agricultura e da indústria, na base das estruturas que desenvolveram em mútua oposição.

Essa nova síntese é expressa no termo "industrialização da agricultura”, onde o campo se converte em fábrica, num ramo da própria indústria, fazendo desaparecer a agricultura enquanto setor autônomo. O processo de industrialização significa que o capital pode 
libertar o processo de produção das amarras representadas pelas condições naturais, passando a fabricá-las sempre que se fizerem necessárias. "A produção agropecuária deixa, assim, de ser uma esperança ao sabor das forças da natureza para se converter numa certeza sob o comando do capital" (SILVA, 1981, p. 43-44). A nova síntese é a própria fabricação da natureza, isto é, a reprodução artificial das condições naturais da produção agrícola, representando a própria industrialização da agricultura. Assim, tanto os OGM como as NT cumprem perfeitamente essa função.

Rifkin (1998) aponta indícios do desenvolvimento de um novo patamar da agricultura a partir dos OGMs, como elemento catalisador da industrialização da agricultura, como: (a) o novo campo de pesquisa da cultura de tecidos, com o objetivo de mover mais produção agrícola para ambientes fechados no próximo século. A tecnologia de engenharia genética já permite produzir, por exemplo, volumes comerciais de baunilha em dornas de laboratório - eliminando a planta, o solo, o cultivo, a colheita, e o agricultor; (b) já se visualiza uma forma híbrida de produção agrícola, parte nos campos e parte nas fábricas. Os campos seriam cultivados somente com culturas perenes produtoras de biomassa. As culturas seriam colhidas e convertidas em solução de açúcares utilizando enzimas. A solução seria então conduzida em tubos ou caminhões-tanque até fábricas urbanas e utilizada como fonte de nutrientes para produzir grandes quantidades de polpa através da cultura de tecidos. A polpa seria reconstituída e fabricada em diferentes formatos e texturas para mimetizar as tradicionais formas associadas com culturas produzidas na terra; (c) as novas fábricas seriam altamente automatizadas e empregariam poucos trabalhadores; ou seja, surgirá a "agricultura de laboratório" altamente mecanizada, sendo que a única parte do processo que necessitaria permanecer a campo seria a captura de energia do sol em plantações de biomassa.

Futurologias à parte, o capital tende a promover a reunificação da agricultura à indústria sob o seu comando, na medida em que se desenvolvem as forças produtivas da indústria (máquinas agrícolas, indústria química e de produtos biológicos, etc.) e, portanto, da ciência e da tecnologia. Antes mesmo da Revolução Industrial, a agricultura já vinha se transformando crescentemente num ramo particular da indústria, seja no sentido de consumo de produtos 
industrializados, seja no fornecimento de matérias-primas para as indústrias. De início, houve a separação embrionária, para chegar aos dias atuais, onde cada vez mais as atividades produtivas no campo se tornam caudatárias do processo industrial. A agricultura se torna crescentemente uma espécie de laboratório onde novos produtos e processos são testados e experimentados para alterar as condições de produção e produtividade do trabalho gerais da sociedade. O capital passa a produzir os meios de produção necessários à agricultura, de forma melhor e mais barata do que os camponeses eram capazes de fazer.

No entanto "o processo de transformação moderna da agricultura atinge uma altura particular quando as conquistas da ciência moderna, a mecânica, a química, a fisiologia vegetal e animal, se transferem das cidades, onde foram elaboradas, para os campos" (KAUTSKY, 1980, p. 59). Os agrotóxicos são desenvolvidos a partir do uso de substâncias químicas desenvolvidas para uso na I Guerra. A indústria genética que se desenvolve a partir dos anos 1930 é catapultada nos anos 1960, como a grande esperança posta pela revolução verde, de superação da fome e miséria no mundo subdesenvolvido. Amplos programas de melhoramento genético foram aplicados, combinando a utilização de sementes melhoradas com a adoção de pacotes químicos e da mecanização.

Do ponto de vista capitalista, essas estratégias deram conta de elevar a produção e a produtividade da agricultura a níveis nunca vistos anteriormente. Mas esses desígnios guiam-se unicamente pela obtenção do lucro máximo e não necessariamente respondem aos imperativos de organização de sociedades justas, solidárias e nem tampouco ambientalmente sustentáveis, tarefas que o capitalismo não tem condições nem interesse de dar respostas. Isso explica porque mesmo com o aumento do volume de produção de alimentos, também tenham crescido a fome, a degradação ambiental e a miséria no mundo.

\section{A NANOTECNOLOGIA COMO NOVO PARADIGMA DA INTER- VENÇÃO FISICO-QUÍMICA NA AGRICULTURA?}

Como visto, o desenvolvimento capitalista da agricultura e fundamentalmente a captura da Ciência e Técnica pelo capital tem levado a um crescente revolucionamento das condições de produção 
na agricultura mundial. Hoje os transgênicos já representam a maioria dos cultivos de soja, milho e algodão e, a depender dos interesses das grandes empresas detentoras dessas tecnologias e de seu controle sobre o mercado de sementes, cada vez mais cultivos se incorporarão ao domínio da transgenia, a não ser que fatos graves relacionados à saúde e ao meio ambiente possam frear esse processo (CHRISTOFFOLI, 2009; SERALINI et al., 2012).

A introdução das tecnologias, em escala Nano, também tem jogado um papel importante, ainda que mais modesto, até o momento, sobre o revolucionamento das condições de produção e da produtividade do trabalho agrícola. Segundo as Nações Unidas (FURLANETTO, 2011, p. 2) áreas possíveis de aplicações da nanotecnologia na agricultura são:

1) Nanofertilizantes para a liberação lenta e uso eficiente da água pelas plantas e fertilizantes;

2) Nanocidas ou pesticidas encapsulados em nanopartículas para liberação controlada, ou nanoemulsão, para sua maior eficiência;

3) Nanopartículas para a conservação do solo;

4) Fornecimento de nutrientes e medicamentos para pecuária e pesca;

5) Nanoescovas e membranas para purificação de água e o solo,

6) Limpeza de viveiros e nanossensores para a qualidade do solo e de vigilância sanitária vegetal, e para a agricultura de precisão.

As atuais tecnologias nano interferem mais diretamente no tempo de trabalho dos agricultores, resultando em otimização de custos referentes à melhor utilização de adubos e agrotóxicos (aumento da produtividade por unidade de princípio ativo utilizada), na maior eficácia prometida com o desenvolvimento de novas drogas para a sanidade animal e maior durabilidade de produtos no pós-colheita. Portanto, redução nas perdas de alimentos que hoje facilmente supera os $30 \%$ do volume total produzido no segmento de hortaliças no Brasil, segundo avaliações do setor (VILELA et. al. 2003), e que é significativo também em outros segmentos como os de grãos e frutas. 
A introdução da nanotecnologia representa do ponto de vista do capital a possibilidade de redução do tempo de trabalho socialmente necessário para a produção de mercadorias na agricultura, reduzindo assim o valor trabalho necessário à produção de mercadorias alimentícias, e de insumos e instrumentos necessários à produção agrícola. É, portanto, uma nova fronteira de valorização do capital (FOLADORI, 2012). Essa redução tende a diminuir o valor de troca dessas mercadorias, viabilizando ainda mais a agricultura de larga escala, pondo em risco a sobrevivência do segmento familiar de pequenos agricultores, incapazes de alcançar as escalas das grandes unidades capitalistas de produção agrícola e aumentando o lucro das corporações nacionais e transnacionais detentoras do oligopólio no fornecimento de insumos e produtos para a agricultura.

Foladori (2012) aborda a contradição entre a velocidade de lançamento de novos produtos contendo componentes nanotecnológicos e a quase absoluta carência de estudos dos impactos sobre a saúde e meio ambiente da escala nano. Esse aspecto, também se faz presente na questão dos OGM, onde a falta de pesquisas aprofundadas e independentes tem comprometido a adequada compreensão do risco trazido pelos mesmos. O capital, como sempre, privatiza lucros e socializa perdas, dramas e custos sociais, remetendo ao Estado a cobertura dos eventuais custos com tratamentos de saúde, aposentadorias, recomposição ambiental, etc.

\section{CONCLUSÕES}

As novas tecnologias e as alterações na lei de patentes, que permitiram a introdução de transgênicos e produtos nanotecnológicos estão resultando em profundas transformações na forma de produzir na agricultura, trazendo riscos sanitários e ambientais inimagináveis até pouco tempo. A sociedade brasileira e mundial, e as organizações de trabalhadores ainda não estão devidamente preparadas para lidar com essas tecnologias, e seus impactos econômicos, sociais e para a saúde e meio ambiente precisam ser melhor estudados. Urgem ações de Estado visando assegurar o princípio da precaução para lidar com ambas tecnologias emergentes. 


\section{REFERÊNCIAS}

CHRISTOFFOLI, Pedro I. O processo produtivo capitalista na agricultura e a introdução dos organismos geneticamente modificados: o caso da cultura da Soja Roundup Ready (RR) no Brasil. 2009. 318 f. Tese (Doutorado em Desenvolvimento Sustentável)-Universidade de Brasília. Brasília, 2009.

FOLADORI, Guillermo. La revolución tecnológica y sus impactos a la salud de los trabajadores. Temporalis, Brasília, ano 12, n. 24, jul./ dez. 2012.

FURLANETTO, Fernanda. Nanotecnologia no setor agropecuário. Pesquisa e Tecnologia, São Paulo, n. 69, v. 8, out. 2011.

KAUTSKY, Karl. A questão agrária. 3. ed. São Paulo: Proposta Editorial, 1980.

MARX, Karl. O capital, Livro III. São Paulo: Abril Cultural, 1988.

Marx, Karl. O capital, Vol I. Rio de Janeiro: Civilização Brasileira, 1968.

RIFKIN, Jeremy. The biotech century. Harnessing the gene and remaking the world. New York: Penguin Putnam, 1998.

SERALINI, G-E., et al. Long term toxicity of a Roundup herbicide and a Roundup-tolerant genetically modified maize. Food and Chemical Toxicology. Disponível em: <http://www.sciencedirect.com/ science/article/pii/S0278691512005637>. Acesso em: 14. out. 2012.

SILVA, José Graziano. Progresso técnico e relações de trabalho na agricultura. São Paulo: HUCITEC, 1981.

VILELA, Nirlene J. et al . O peso da perda de alimentos para a sociedade: o caso das hortaliças. Hortic. Bras., Brasília, v. 21, n. 2, jun. 2003. Disponível em: <http://www.scielo.br/scielo.php?script=sci_ arttext\&pid=S01025362003000200002\&lng=en\&nrm=iso >. Acesso em: 14 out. 2012. 